\title{
INTERSECCIONALIDADE EM UMA ERA DE GLOBALIZAÇÃO AS IMPLICAÇÕES DA CONFERÊNCIA MUNDIAL CONTRA O RACISMO PARA PRÁTICAS FEMINISTAS TRANSNACIONAIS
}

\author{
MAYLEI BLACKWELL \\ Loyola Marymount University
}

NADINE NABER

American University

Resumo: Este relatório analisa a interseccionalidade como uma abordagem feminista com significante impacto nos discursos e debates duranfe o Fórum de ONGs e a Conferência Mundial Contra o Racismo, em Durban, África do sul. O termo 'interseccionalidade' se refere às articulações entre a discriminação de gếnéro, a homofobia, o racismo e a exploração de classe. Falando do lugar de enunciação de mulheres de cor feministas situadas nos territórios geográficos dos Estados Unidos, as gytoras enfatizam algumas questões-chave e tendências dos movimentos sociais que foram ignoradas pela mídia estadunidense. Alternativamente, 0 relatório examina como a introdução das 'ihfolerâncias correlatas' na agenda da Conferência permitiu discussões mais amplas søbre os efeitos dar globalização no agravamento do racismo e sobre as múltiplas opressões com relação ơ orientação sexual e aos direitos sexuais. As autoras argumentam que uma insistência na significância do gênero e da raça, bem como da classe, no contexto do capitalismo neo-liberal, coloca novas e importantes coordenadas nos mapas do feminismo transnacional e do crescente movimento anti-globalização.

Palovras-chove: interseccionalidade, gênero, racismo, sexualidade, globalização, feminismo transnacional.

Enquanto preparávamos este relato, buscávamos resgatar o significado da Conferência Mundial das Nações Unidas contra o Racismo das ruínas causadas pela primeira semana de bombardeios americanos no Afganistão e da devastação e perda maciça de vidas nos ataques ao World Trade Center, ao Pentágono e na Pensilvânia. ${ }^{1}$ Como uma linha de demarcação histórica dividindo nossos corações e nossa noção do tempo - antes e depois de 11 de setembro - ativistas e organizadoras, ao retornarmos de

Copyright (C) 2002 by Revista Estudos Feministas

1 Publicado originalmente como "Intersectionality in an Era of Globalization: The Implications of the U.N. Conference against Racism for Transnational Feminist Practices". Meridians: A Journal of Feminism, Race, Transnationalism, v. 2, n. 2, p. 237-248, 2002. Traduzido para o português com permissão da editora. Copyright (c) 2002 by Wesleyan University Press. 
Durban, descobrimos que o terreno político havia se movido sob nossos pés com uma intensidade que levaríamos décadas para avaliar. Apesar dos tempos difíceis, mais do que nunca precisamos da mensagem e das lições obtidas desse histórico encontro contra o racismo, no momento em que histórias nos chegam de todas as partes do país sobre os mais de 700 casos de crimes de ódio contra americanos árabes ou tidos como árabes, na sua maioria membros de comunidades sul-asiáticas. O contexto político pós-11 de setembro não só testemunhou um aumento da violência racista, como também assistiu à implementação de políticas regressivas, que incluem a prisão por prazo indeterminado e a renovação de políticas antiimigração, tais como o uso de 'evidência secreta' como motivo para detenção e deportação.

\section{Confrontando o racismo na era da globalização}

Apesar do virtual silêncio da mídia, a Conferência Mundial contra o Racismo, Discriminação Racial, Xenofobia e Intolerâncias Correlatas se constituiu em um encontro histórico do movimento global anti-racismo em todas as suas diversas manifestações. Embora o século XXI tenha começado com a Conferência Mundial contra o Racismo (31 de agosto a 7 de setembro) e com a de Organizações Não-Governamentais (ONGs) que se desenvolveu em paralelo, a preocupação das Nações Unidas com questões de racismo e a malfadada participação do governo dos Estados Unidos nessa conferência têm uma história mais longa. A Assembléia Geral das Nações Unidas designou o ano de 1971 como o Ano Internacional do Combate ao Racismo e à Discriminação Racial e, antes de Durban, duas Conferências Mundiais contra o Racismo tiveram lugar em Genebra em 1978 e em 1983. Os Estados Unidos boicotaram as duas.

O Fórum de ONGs em Durban atraiu entre 8 mil e 10 mil delegados/as, em sua maioria mulheres, de nações de todas as partes do mundo. $O$ encontro tratou de temas como colonialismo, crimes de ódio e violência, purificação étnica, migrações/refugiados, escravidão e tráfico de escravos, pobreza e exclusão social, racismo institucionalizado, anti-semitismo, discriminação por casta, gênero, orientação sexual, juventude, ocupação estrangeira, racismo ambiental, intolerância religiosa, reparações, trabalho, tráfico e globalização. Como um caso exemplar, a África do Sul simbolizou tanto a vitória sobre o apartheid quanto a tenacidade dessa virulenta forma de racismo sistemático. Na África do Sul, ativistas anti-apartheid enfatizaram que, sem justiça econômica, seu movimento continua sendo uma revolução inacabada e que ainda há um longo percurso até que uma verdadeira igualdade racial seja estabelecida nas cada vez mais difíceis condições criadas pela globalização.

Na verdade, as formas pelas quais a luta contra o racismo e a globalização se manifestou passaram desapercebidas ou foram ignoradas pela mídia. Além do Fórum de ONGs e da Conferência Governamental, uma terceira arena política surgiu em Durban, como conseqüência de uma greve geral de dois dias com passeatas lideradas pelo Congresso dos Sindicatos Sul-Africanos e uma marcha de aproximadamente um milhão de trabalhadores em Johannesburg. Muitos participantes das ONGs juntaram-se aos manifestantes sul-africanos antiglobalização para protestar contra a privatização. No dia 31 de agosto, mais de 30 mil pessoas foram às ruas para uma marcha organizada pelo Fórum Social de Durban em solidariedade com o movimento dos sem-terra, que criticava o fracasso do Congresso Nacional Africano (African Nacional Congress) de manter sua promessa de "terra para quem nela trabalha". Pelo fato de a Conferência Mundial contra o Racismo ter sido inacessível a muitos sul-africanos, as ruas se transformaram em um fórum multitemático para os participantes da conferência internacional e para os militantes locais, 
no qual a questão de classe se destacou em meio às discussões sobre os sistemas de opressões inter-relacionadas que constituem $\circ$ racismo. ${ }^{2}$ A natureza abrangente da globalização e as condições por ela criadas - especialmente para os pobres, as mulheres e os racialmente marginalizados - manifestou-se como uma tendência mestra subjacente à Conferência Mundial contra o Racismo. Como um local-chave para a continuação de um crescente movimento internacional antiglobalização, Durban foi especial, pois, diferentemente das demonstrações contra a globalização que tiveram lugar em Seattle (1999) e Gênova (2001), atraiu predominantemente pessoas de cor das Américas, da África e da Ásia. ${ }^{3}$ Em Durban, queixas contra a globalização enfatizaram a exploração econômica e o racismo simultaneamente, não só em relação às instituições financeiras transnacionais, mas em termos de como essas instituições estão também ligadas a formas persistentes de colonialismo, imperialismo e apartheid que são freqüentemente excluídas dos debates correntes da antiglobalização.

Participamos da Conferência Mundial contra o Racismo como membros de uma delegação nacional de ativistas e pesquisadoras de orientação comunitária organizada pelo Centro de Recursos para Mulheres de Cor (Women of Color Resource Center) em Berkeley, Califórnia. Armadas com um relatório alternativo preparado para a Conferência Mundial contra o Racismo, intitulado "Tempo de rebelar-se: questões e estratégias das mulheres de cor dos Estados Unidos", nossa crítica principal era a de que os círculos políticos dos Estados Unidos costumam tratar problemas de violência, pobreza, trabalho e globalização como questões de interesse internacional em vez de questões imediatas que têm um profundo impacto nas mulheres de cor de nossas próprias comunidades locais. ${ }^{4}$ Nas páginas que seguem, traçamos os principais acontecimentos que não foram reconhecidos pela mídia estadunidense e indicamos o papel dos Estados Unidos, não só na configuração dos debates mas também no policiamento dos limites daquilo que podia ser discutido e debatido. As ameaças dos Estados Unidos chegaram às raias da censura ao evitar que certos temas fossem abordados e que certas linguagens fossem usadas, conforme ilustrado pelos esforços para sabotar qualquer tentativa de definir a escravidão como um crime contra a humanidade ou falar de sionismo como uma forma de racismo. Para entender as complexas manobras em Durban, é importante constatar que no âmago da Conferência Mundial contra o Racismo havia uma disputa discursiva, ou uma disputa a respeito da representação e do poder de definir, o que tem sido um dos aspectos centrais da dominação colonial e da legitimação através da história.

\section{Travessia perigosa: o gênero na intersecção de raça e pobreza}

Após décadas de esforço para conseguir que os impactos gendrados do racismo, da xenofobia e da violência fossem reconhecidos, esse foi o primeiro encontro contra o racismo patrocinado pelas Nações Unidas que incluiu 'intolerâncias correlatas', ou seja, os modos pelos quais o racismo se intersecta com a pobreza, a discriminação de gênero e a homofobia. O Grupo de Discussão das Mulheres (Women's Caucus) enfatizou que, se não fosse dada atenção ao gênero, certas formas de racismo passariam desapercebidas. ${ }^{5} \mathrm{O}$

\footnotetext{
${ }^{2}$ Milhares de sul-africanos locais foram proibidos de participar do Fórum de ONGs e da Conferência, e não conseguiram acomodação em Durban. Por exemplo, 350 mulheres sul-africanas tiveram que dormir em vagões de trem, em condições precárias, com apenas um banheiro, mesmo tendo se inscrito para o encontro com antecedência.

${ }^{3}$ Frances BEAL, 2001.

${ }^{4}$ Maylei BLACKWELL et al., 2001.
} 
gênero foi incorporado a várias arenas importantes, como o Grupo sobre Globalização e Pobreza, o Grupo de Trabalho sobre Direitos dos Migrantes, o Grupo de Africanos e Descendentes de Africanos, no trabalho de solidariedade aos Palestinos, entre outras.

Testemunhos de trabalhadoras migrantes das Filipinas, ativistas lésbicas da África do Sul e de mulheres palestinas nos acampamentos de refugiados foram fundamentais na construção de alianças feministas. Viola Casares, da Fuerza Unida, uma organização de trabalhadoras de origem latino-americana, precursora do movimento antiglobalização, testemunhou que as conexões entre globalização e racismo criam condições nas quais

mulheres de cor, mulheres pobres e aquelas que não têm uma educação adequada são tripudiadas, discriminadas e oprimidas como se não tivessem valor algum. Sabemos que a globalização aumenta a violência existente em nossas comunidades, especialmente a violência doméstica e a violência contra crianças nas comunidades de cor. (...) Não quero que ninguém sinta pena (...) de nós. Nós, e outras mulheres que encontramos [em Durban], somos fortes e continuaremos a lutar. (...) Isso foi o que ouvi de todas as mulheres que conheci, de todas as partes do mundo. Somos mães, irmãs, esposas, companheiras, avós, trabalhadoras, filhas e luchadoras, ou seja, lutadoras. (...) Entendemos a relação entre globalização e racismo. Participar deste encontro nos fortaleceu. (...) Não abriremos mão de nossas culturas e não seremos separadas pela raça. ${ }^{6}$

O que aprendemos sobre a participação das mulheres no movimento dos sem-terra na África do Sul, na Intifada, na luta dalit e no movimento indígena nos lembrou de que, embora sejamos a espinha dorsal de nossos conflitos, nós, mulheres, permanecemos à margem nas políticas masculinistas de liberação nacional e nas lutas comunitárias contra o racismo. Não obstante as 'intolerâncias correlatas' terem aberto espaço para novas alianças e análises mais complexas na luta contra o racismo, o tópico foi freqüentemente criticado pelos conservadores como uma estratégia para enfraquecer a agenda anti-racista, e mesas-redondas e oficinas organizadas em torno do gênero ficaram muitas vezes marginalizadas dentro do âmbito maior dos debates sobre raça. Apesar desses desafios, ficou claro que as mulheres permanecem na linha de frente da luta, do planejamento estratégico e da coalizão, e que estão construindo uma abordagem globalmente mais integrada ao trabalho contra o racismo.

\section{Quem carrega o peso da história? A questão das reparações}

O Grupo de Africanos e Descendentes de Africanos consolidou uma estratégia para influenciar a Conferência Mundial contra o Racismo em três questões: (1) o tráfico transatlântico de escravos, a escravidão e o colonialismo como crimes contra a humanidade; (2) reparações para as vítimas do tráfico de escravos, da escravidão e do colonialismo; e (3) a base econômica do racismo. Os países africanos, na sua maioria, permaneceram comprometidos a discutir as reparações, apesar das tentativas dos Estados Unidos e da União Européia para calar o debate. Enquanto alguns governos insistiam em

\footnotetext{
${ }^{5}$ Um Grupo de Discussão de Mulheres de mais de 40 ONGs, representando todas as regiões do mundo, foi constituída na Primeira Reunião Preparatória (PrepCom) da Conferência Mundial contra o Racismo, de $1^{\circ}$ a 5 de maio de 2000. Ver, por exemplo, Kimberlé Crenshaw, "The Intersectionality of Race and Gender Discrimination", uma Declaração de Intenções e Oficina Preparatória do Fórum de Políticas Afro-Americanas, bem como o trabalho desenvolvido pelo Fundo das Nações Unidas para o Desenvolvimento das Mulheres (UNIFEM), "Integrating Gender into the Third World Conference against Racism, Racial Discrimination, Xenophobia and Related Intolerance". Disponível em $<$ www.unifem.und.org/hr_racism.html $>$.

${ }^{6}$ Viola CASARES, 2001 , p. 10.
} 
abordar apenas o 'racismo atual' e não crimes históricos, muitos ativistas enfatizaram que a escravidão é uma prática contemporânea, em andamento. Ativistas pelos direitos de prisioneiros nos Estados Unidos caracterizaram o encarceramento de pessoas de cor em prisões como uma forma de escravidão em nossos dias. Em um encontro regional da Comissão de Gênero, mulheres africanas acrescentaram que a escravidão moderna continua através do tráfico de mulheres e de jovens, usadas como escravas para fins sexuais e para mão-de-obra, nas mais deploráveis condições e sem qualquer remuneração. Tais condições, argumentaram, levam a uma situação de desgoverno e à disseminação de doenças sexualmente transmissíveis, como HIVIAIDS, muitas vezes através da violência sexual. Insistiram que as mulheres são o grupo mais vulnerável no contexto das formas históricas e contemporâneas de colonialismo e de escravidão. ${ }^{7}$ Dois meses se passaram desde Durban, e o Secretariado das Nações Unidas ainda não divulgou a Declaração e o Programa de Ações finais, em parte devido a uma disputa entre Estados para reconhecer três parágrafos que solicitam a condenação e desculpas pela escravidão e pelo tráfico transatlântico de escravos, de apartheid, colonialismo e genocídio, e que pedem que "Estados envolvidos tomem medidas corretivas adequadas para eliminar e reverter as duradouras conseqüências de tais práticas". Apesar desses problemas, existe um consenso geral entre ativistas pró-reparação de que a Conferência foi um grande sucesso que ajudou o movimento nos Estados Unidos a reorientar uma estreita agenda nacional em direção a um crescente movimento internacional.

\section{' $S$ ' significa soberania: povos indígenas e a Conferência Mundial contra o Racismo}

Como um movimento que vem funcionando há décadas dentro das Nações Unidas, o Grupo dos Povos Indígenas ficou restrito à luta contra os usos racistas e discriminatórios representados pela letra 'S' na Conferência Mundial contra o Racismo. Os povos indígenas têm defendido o uso do termo 'povos', em oposição a 'povo' ou 'população', porque, no direito internacional, o termo 'povos' aciona o direito à autodeterminação. Mesmo assim, Estados se aproveitaram da conferência para minar o direito à autodeterminação, assim enfraquecendo o prestígio e os direitos básicos da população mundial de povos indígenas, estimada em 300 milhões de pessoas. O Grupo dos Povos Indígenas lutou para assegurar que a Declaração da Conferência Mundial contra o Racismo, documento que estabeleceria parâmetros internacionais, não se constituísse em um documento regressivo que faria o movimento indígena internacional retroceder anos, ou mesmo décadas. ${ }^{8}$

Durante a Conferência Mundial contra o Racismo, os Estados Unidos e outros governos finalmente concordaram com o emprego do termo 'povos indígenas', desde que despojado de seu significado com relação à autodeterminação, ao estipularem que "o uso do termo povos neste documento não deve ser visto como tendo qualquer implicação com os direitos atrelados a ele nas leis internacionais". "Essa ressalva implica que os direitos humanos dos povos indígenas não são inerentes ou inalienáveis, mas dependentes

\footnotetext{
${ }^{7}$ Mary WANDIA e Atsango CHESONI, 2001.

${ }^{8}$ Cinco anos após a primeira Conferência Internacional sobre Discriminação contra Povos Indígenas, ocorrida em 1977 em Genebra, foi formado o Grupo de Trabalho sobre Populações Indígenas. As Nações Unidas designaram 1993 como o Ano Internacional dos Povos Indígenas do Mundo e 1995-2004 como a Década Internacional dos Povos Indígenas do Mundo. Uma das prioridades da década tem sido a de estabelecer um fórum permanente para povos indígenas dentro das Nações Unidas, destinado a orientar representantes indígenas sobre como se reportar às várias instâncias oficiais das Nações Unidas. Para uma visão histórica desses primeiros esforços, ver Roxanne DUNBAR ORTIZ, 1984.
} 
de leis nacionais, criando assim padrões diferenciados daqueles aplicados mundialmente a outros indivíduos ou grupos.

Mesmo assim, o encontro em Durban e o processo de preparação para a Conferência demonstraram um continuado crescimento na organização internacional indígena. ${ }^{10}$ Mulheres indígenas demonstraram liderança na articulação de lutas internacionais e comunitárias. Por exemplo, o objetivo das mulheres indígenas do México era trazer sua situação para a arena internacional após o Parlamento de seu país ter aprovado neste ano um projeto de lei sobre direitos dos índios que entra em choque com os mais básicos princípios do Acordo de San Andrés, assinado pelo Exército Zapatista de Libertação Nacional e o governo em 1996. Cándida Jimenez, do povo mixe, organizadora da Coordenação Nacional de Mulheres Indígenas do México, que trabalha com direitos reprodutivos e autonomia, enfatizou que, embora os povos indígenas e suas culturas milenares tenham sobrevivido ao colonialismo e ao capitalismo, há uma crescente necessidade de união enquanto povos indígenas para questionar a globalização neoliberal. Conta ela que o movimento indígena no México, uma expansão nacional da revolta de Chiapas, em 1994, busca novas estratégias de resistência depois da traição dos Acordos de San Andrés, ao mesmo tempo que enfrenta novas formas de militarização e o crescimento de zonas de livre comércio, conforme proposta no Plano Pueblo to Panama.

\section{Sionismo: o 'ismo' esquecido}

Participantes da Conferência Mundial contra o Racismo envolvidos com a questão palestina apontaram Israel como o Estado do racismo, da exclusão e do apartheid. Argumentaram que os métodos empregados para garantir a supremacia racial, na manutenção do Estado de Israel como exclusivo "apenas para judeus", incluem "a continuada desapropriação e destruição da terra, da agricultura e dos lares palestinos, a recusa de direitos de residência, a separação de famílias e comunidades, severas restrições do direito de ir e vir (...) e, mais recentemente, o aprisionamento virtual através do uso de trincheiras e portões com chaves guardadas por soldados israelenses". ${ }^{11}$ Uma razão fundamental para a ameaça dos Estados Unidos de se retirar da III Conferência, sob o argumento de que a agenda incluía a discussão do sionismo como uma forma de racismo, foi o documento final do Fórum de ONGs, que propunha uma condenação da violação sistemática dos direitos palestinos por parte de Israel.

Participantes sionistas da Conferência, para minar as queixas dos palestinos contra Israel, empenharam-se em uma campanha de atos simbólicos orientada para a mídia, que incluiu a distribuição de cravos brancos e a música "Dê uma chance à paz" (Give Peace a Chance). Isso, um dia após os israelenses terem assassinado um importante líder civil palestino. ${ }^{12}$ Outras táticas consistiam na interrupção de debates sobre a Palestina, com cartazes representando estereótipos raciais que afirmavam que os palestinos haviam seqüestrado a Conferência, e tentativas de minimizar as questões palestinas como mera 'política' e, portanto, não-essenciais para a discussão do 'racismo'. Apesar dessas ações,

\footnotetext{
9 O termo 'povos indígenas' é empregado sem qualquer qualificação ou nota explicativa em várias convenções das Nações Unidas, e o direito à autodeterminação é reconhecido por vários organismos da entidade. Muitos ativistas indígenas alegam que o fato de estas noções não estarem representadas nos documentos da WCAR põe em risco a credibilidade da Declaração.

${ }_{10}$ Ver, por exemplo, Indigenous Peoples, Racism and the United Nations, o relatório do Encontro Regional de Povos Indígenas sobre a Conferência Mundial contra o Racismo, organizado pela pela Aboriginal and Torres Strait Islander Commission (ATSIC), em Sidney, Austrália, em fevereiro de 2001 (NAKATA, 2001).

1 PALESTINIAN NGO MEDIA TEAM, 2001, p. 3.

${ }^{12}$ Enquanto a atenção mundial se voltava para Durban e para o esforço global para erradicar o racismo, as forças israelenses continuavam seus ataques contra civis palestinos durante todo o período da Conferência. Entre 27 de agosto e 6 de setembro, as forças militares israelenses assassinaram Abu Ali Mustafa, importante líder civil da política palestina, invadiu vilas e cidades, e feriu e matou vários jovens e crianças.
} 
o movimento de solidariedade palestina não só obteve um surpreendente apoio em Durban, como se tornou o ponto de convergência de muitos movimentos populares e de solidariedade representados na Conferência.

Da marcha organizada pelo Congresso dos Sindicatos Sul-Africanos (COSATU), na qual milhares de líderes trabalhistas sul-africanos/as gritavam palavras de ordem com 0 refrão "Viva a Palestina", até o local da Conferência, onde as pessoas que passavam pediam aos palestinos que lhes dessem seus lenços, bótons, camisetas e canetas, emergiu um consenso internacional e multirracial de que Israel é um Estado racista. Lembrando o histórico apoio, inclusive militar, de Israel à segregação racial na África do Sul, sul-africanos/ as identificaram-se com os/as palestinos/as na sua experiência comum de viver sob um regime de apartheid. Um comunicado expedido por quase 3 mil ONGs acusava Israel de ter perpetrado, sistematicamente, crimes racistas, incluindo crimes de guerra, atos de genocídio e de limpeza étnica.

Um dos primeiros exemplos da vitória palestina em Durban foi quando Manar, uma adolescente do campo de refugiados palestinos em Dheisheh, apoiada maciçamente por delegados/as da Cúpula da Juventude, publicamente confrontou Mary Robinson, Alta Comissária das Nações Unidas para os Direitos Humanos, perguntando por que ela não havia incluído a Palestina na lista de questões que seriam discutidas na Conferência Mundial contra o Racismo. Mary Robinson, então, voltou ao microfone e anunciou que o sofrimento do povo palestino seria discutido na Conferência. Em outra ocasião, em um debate sobre interseccionalidade e globalização, mulheres palestinas explicaram o impacto da ocupação israelense na fragmentação dos movimentos de mulheres palestinas. Em um painel sobre mulheres de cor dos Estados Unidos, as árabe-americanas argumentaram que o sionismo é o 'ismo' esquecido pelos movimentos feministas norte-americanos. Explicaram que são racializadas em relação ao movimento sionista, especialmente quando feministas sionistas, estrategicamente, (con)fundem anti-sionismo (crítica às políticas do Estado de Israel) com anti-semitismo. E acrescentaram que a demonização das mulheres árabes no contexto da mídia ocidental é muitas vezes utilizada para justificar a violência de Israel contra o povo árabe. ${ }^{13}$

\section{Novas tendências/novos atores: lutas anti-racistas}

Entre ativistas anti-racistas, 'intolerâncias correlatas' também significaram a introdução da idéia de opressões múltiplas com relação à orientação sexual e direitos sexuais. ${ }^{14}$ Embora pouco progresso tenha sido feito na Declaração e no Programa de Ação, o fato de a discussão ter acontecido introduz novas e importantes coordenadas na curva de aprendizado global que ajudará ativistas gays, lésbicas, bissexuais e transexuais a continuar estabelecendo novos diálogos sobre o modo pelo qual o racismo, a exploração de classe, o gênero e a homofobia se cruzam e se complementam mutuamente..$^{15}$ No Fórum de ONGs e na Conferência Governamental havia uma Comissão de Orientação Sexual, bem como um Grupo de Discussão, além de diversas mesas-redondas e oficinas. No dia $1^{\circ}$ de setembro, uma

\footnotetext{
${ }^{13}$ ARAB WOMEN'S SOLIDARITY ASSOCIATION, 2001.

${ }^{14}$ Svati SHAH et al., 2001.

${ }^{15}$ Este trabalho começou nas primeiras fases da preparação, quando foi organizado um encontro paralelo sobre Racismo, Discriminação e Intolerância à Diversidade Sexual, em Quito, Equador, em março de 2001, sob os auspícios da Latin American South-South Dialogue, da Sub-Região Andina das Associações Internacionais de Gays e Lésbicas e do ALAl Women's Program. Ver a declaração produzida neste encontro em <www.hri.ca/racism/SUMITTED/ theme.gay.htm>. Na segunda reunião do Comitê Preparatório (II PrepCom), em Genebra, houve muita controvérsia quando a Associação Internacional de Gays e Lésbicas teve negado o status de observadora da Conferência Mundial, em uma votação empatada em 43 votos, com abstenções de 27 países.
} 
coalizão de ativistas africanos organizou, com êxito, uma conferência paralela intitulada "Homofobia - o Racismo Interno: racismo, homofobia e abusos dos direitos humanos na África Meridional". 16

Pelo fato de haver tanta heterogeneidade nas formas como a raça é estruturada em torno da classe sócio-econômica, dos padrões culturais, das diferenças regionais e das histórias coloniais semelhantes ou divergentes, um aspecto crucial da Conferência foi a educação global que os ativistas proporcionaram uns aos outros sobre as mais diversas formações raciais. Entre os principais atores que emergiram nesse palco mundial incluemse os/as dalits, que, apesar de terem sido historicamente caracterizados/as como intocáveis na Índia, nos ilustraram a complexidade das várias formas de discriminação racial em termos de discriminação de castas. Os povos Roma chamaram a atenção para a xenofobia e outras discriminações enfrentadas por populações migrantes. Além disto, paralelamente à Conferência Mundial contra o Racismo, também foi realizada a Cúpula Global da Juventude, na qual jovens de todas as partes do mundo compartilharam suas histórias e suas visões de um mundo diferente e, assim, expandiram a agenda da Conferência.

\section{Conclusões e desafios}

Será que um documento, Plano de Ação ou Declaração poderá erradicar o racismo? O que significam essas disputas sobre linguagem, histórias e discursos, afinal? A importância da Conferência Mundial contra o Racismo está no estabelecimento de normas internacionais às quais os Estados devem responder; na contribuição para um diálogo em torno de opressões comuns em um contexto internacional; no alargamento de nossa definição de racismo e de como, em sua complexidade, ele se intersecta com múltiplas formas de opressão. Contudo, a solução para uma organização transnacional efetiva é trazê-la 'para casa' - esse é nosso desafio e nossa lição. A efetividade da Declaração ou do Plano de Ação consiste em não deixá-los para trás, como palavras vazias, mas usá-los em nossas lutas diárias contra o racismo e suas complexas intersecções.

O encontro em Durban foi um evento-chave para o crescente movimento antiglobalização, tendo enfatizado as muitas maneiras pelas quais a globalização depende da estratificação racial, da discriminação sexual e da exploração de classe. Como participantes em diferentes espaços de ação política em Durban - o Fórum de ONGs, a Conferência Governamental e a mobilização de massa nas ruas - fomos tocadas pela constatação de que havia diferentes agendas, diferentes grupos de interesse e atores, bem como diferentes modos de fazer política em cada uma dessas arenas. Na Conferência Mundial contra o Racismo, essas "lógicas do movimento transnacional", ${ }^{17}$ distintas, imbricadas, às vezes incompatíveis, variavam desde as mobilizações antiglobalização das classes trabalhadoras até a crescente profissionalização dos movimentos sociais, requerida para funcionar dentro da estrutura das Nações Unidas. Embora historicamente conhecido por proporcionar um espaço mais amplo para a participação de movimentos sociais, o Fórum de ONGs, em Durban, foi criticado pela infra-estrutura e pela organização insuficientes, o que diminuiu seu foco político e sua eficiência. Ativistas criticaram a crescente profissionalização, a natureza excludente das estruturas das ONGs e um Fórum cuja organização refletia a da Conferência Governamental em vez de proporcionar uma esfera alternativa a partir da qual se pudesse dialogar com os Estados e suas delegações e influenciá-los.

\footnotetext{
16 Organizada pelo Centro Comunitário e de Saúde Gay e Lésbico, de Durban, pelo Projeto de Igualdade Gay e Lésbica, pelo Projeto Arco-Íris, da Namíbia, e pelos Gays e Lésbicas do Zimbábue.

${ }^{17}$ Sonia E. ALVAREZ, 2000.
} 
Se Durban pode servir de indicador, talvez seja 'do lado de fora' das trincheiras da estrutura formal das Nações Unidas que um fórum alternativo de ação e participação das massas esteja se formando. A Conferência Mundial contra o Racismo pode talvez indicar uma crescente tendência para a formação de 'contrapúblicos' transnacionais alternativos, com seus próprios atores, público-alvo, agendas e 'lógica'. Embora a multiplicação de campos de participação seja um desenvolvimento positivo, devemos observar que esse crescimento foi causado por impedimentos a uma efetiva participação e uma falta de acesso a fóruns tradicionais de representação política. Alguns dos constantes problemas de organização transnacional refletiram-se na Conferência Mundial contra o Racismo como um todo, e nos fóruns de mulheres em particular, já que a dinâmica da Conferência reproduziu as hierarquias norte/sul e marginalizou pessoas com base em sua origem lingüística. Pontes ainda têm que ser construídas entre essas distintas arenas políticas, que permanecem segregadas por linhas demarcatórias de classe e de capital cultural. Os múltiplos espaços de resistência para as mulheres nessa Conferência apareceram em toda sua complexidade. Aprendemos que coalizões feministas transnacionais, para serem efetivas, devem ancorar nosso crescente entendimento global do racismo, tanto em uma visão mais ampla de globalização, colonialismo e imperialismo quanto em uma visão mais aproximada do modo como relações de raça, classe e gênero estão, freqüentemente, imbricadas a histórias locais, a formações culturais e a relações de poder.

\section{Referências bibliográficas}

ALVAREZ, Sonia E. "Translating the Global: Effects of Transnational Organizing on Latin American Feminist Discourses and Practices". Meridians: A Journal of Feminism, Race, Transnationalism v.1, n. 1, p. 29-97, 2000.

ARAB WOMEN'S SOLIDARITY ASSOCIATION. "The Forgotten '-ism': An Arab-American Women's Perspective on Zionism, Racism and Sexism". In: BLACKWELL, Maylei, BURNHAM, Linda, and CHOI, Jung Hee (eds.). Time to Rise: U.S. Women of Color - Issues and Strategies. Berkeley: Women of Color Resource Center, 2001. p. 149-170.

BEAL, Frances. "War, Racism and Repression: The Times that Try One's Soul". Discurso proferido em um fórum auspiciado pelo Black Radical Congress. Oakland, California, 28 out. 2001.

BLACKWELL, Maylei, BURNHAM, Linda, and CHOI, Jung Hee (eds.). Time to Rise: US Women of Color - Issues and Strategies. Report to the UN World Conference against Racism, Racial Discrimination, Xenophobia and Related Intolerance. Berkeley, California: Women of Color Resource Center, 2001.

CASARES, Viola. "De San Antonio a Durban con La Fuerza Unida: a platica with Viola Casares and H. Esperanza Garza". La Voz de Esperanza, v. 14, n. 4, p. 11, 2001.

DUNBAR ORTIZ, Roxanne. Indians of the Americas: Human Rights and Self-determination. New York: Praeger Publishers, 1984.

SHAH, Svati P. et al. "Intersection of Race and Sexuality". Background paper commissioned by the International Gay and Lesbian Human Rights Commission and the Astraea Lesbian Action Foundation, 2001.

NAKATA, Martin (ed.) Indigenous Peoples, Racism and the United Nations. Sydney, Australia: Common Ground Publishing, 2001.

PALESTINIAN NGO MEDIA TEAM. "Palestinian NGO Bulletin: World Conference Against Racism." August 20, 2001.

WANDIA, Mary and CHESONI, Atsango. "African Women Share Experiences and Identity Priorities". Femnet Issue 2, p. 1-3, 2001. Women's on-line bulletin published during the World Conference Against Racism. Available at: <www.africaonline.co.ke/femnet> 
Tradução Susana Bornéo Funck

Revisão de Luiza Bairros

\begin{abstract}
Intersectionality in an Era of Globalization: The Implications of the U.N. World Conference against Racism for Transnational Feminist Practices

Abstract: This report examines 'intersectionality' as a feminist approach that significantly impacted the discourses and conversations that took place at the World Conference Against Racism and its parallel NGO Forum, in Durban, South Africa in 2001. The term 'intersectionality' refers to the links between gender discrimination, homophobia, racism and class exploitation. As women of color feminist scholars positioned within the geographic territories of the U.S., the authors specifically highlight key issues and social movement trends that were ignored by the U.S. media. Alternatively, this report focuses on how the conference framework of 'related intolerance' allowed for broader conversations on how racism is exacerbated by globalization as well as on multiple oppressions in relation to sexual orientation and sexual rights. The authors emphasize how an insistence on discussing the significance of race and gender as well as class, in the context of neo-liberal capitalism, puts important new coordinates on the maps of transnational feminist organizing and anti-globalization movement.
\end{abstract}

Keywords: intersectionality, gender, racism, sexuality, globalization, transnational feminism. 